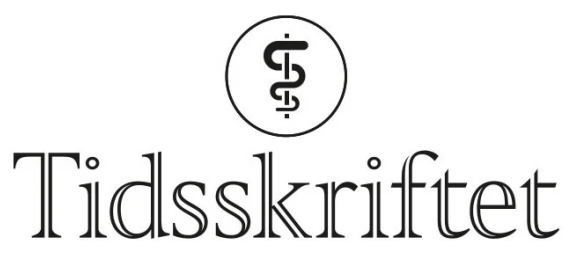

DEN NORSKE LEGEFORENING

\title{
Medikamentell behandling av malaria i Norge
}

LEGEMIDLER I PRAKSIS

KRISTINE MØRCH

Kristine Mørch (f. 1963)

er spesialist i infeksjonssykdommer. Hun er leder av Nasjonal kompetansetjeneste for tropiske

infeksjonssykdommer ved Medisinsk avdeling, Haukeland universitetssykehus.

Forfatter har fylt ut ICMJE-skjemaet og oppgir ingen interessekonflikter.

Email: kristine.morch@helse-bergen.no

Nasjonal kompetansetjeneste for tropiske infeksjonssykdommer

Haukeland universitetssykehus

\section{BJØRN MYRVANG}

Bjørn Myrvang (f. 1940)

er spesialist i indremedisin og i infeksjonssykdommer og er leder av Kompetansesenter for import- og tropesykdommer, Oslo universitetssykehus, Ullevål. Han er professor emeritus, Universitetet i Oslo.

Forfatter har fylt ut ICMJE-skjemaet og oppgir ingen interessekonflikter.

Kompetansesenter for import- og tropesykdommer

Oslo universitetssykehus, Ullevål sykehus

Hvert år ankommer 30-6o pasienter med malaria til Norge. Hos ca. to tredeler er sykdommen forårsaket av Plasmodium falciparum. Falciparummalaria kan raskt bli livstruende, og medikamenter til behandling av alvorlig malaria må være tilgjengelig ved alle norske sykehus. Formålet med denne artikkelen er å gi en anbefaling om medikamentell behandling av malaria i Norge.

\footnotetext{
De siste åtte årene er det meldt 28-61 malariatilfeller årlig til Meldingssystem for smittsomme sykdommer (MSIS), Folkehelseinstituttet (11). Av disse var 57-75\% forårsaket av Plasmodium falciparum, en infeksjon som innebærer betydelig risiko for dødelig utgang dersom ikke diagnosen raskt blir stilt og effektiv behandling gitt (므). Det er viktig å være klar over at livstruende sykdom fort kan utvikle seg selv om pasienten virker relativt upåvirket ved første legekontakt (3). Av 222 pasienter med falciparummalaria som ble diagnostisert i Oslo og Akershus i tidsperioden 1988-97, var $95 \%$ smittet i Afrika (4). Senere har situasjonen vært om lag den samme, og særlig erverver mange infeksjonen i VestAfrika (1).

Leger som står overfor pasienter med mistenkt malaria, skal umiddelbart sende pasientene til sykehus. Det er sykehusets oppgave raskt å avgjøre om pasienten har malaria, hvilken plasmodiumart pasienten er infisert med, og uten forsinkelser innsette korrekt behandling. På sykehus hvor det ikke finnes tilstrekkelig kompetanse til å utføre malariadiagnostikk ved mikroskopi 24 timer i døgnet, bør det finnes hurtigtester for antigenpåvisning.
}

Norsk legemiddelhåndbok for helsepersonell 2010 inneholder et malariakapittel som innbefatter behandling (5). Siktemålet med denne artikkelen er å gi en utfyllende beskrivelse av medikamentell behandling av malaria. Vi regner med at medikamentvalg kan være veiledende for alle som står overfor 
malariapasienter i Norge. Når det gjelder behandling av barn vises det til retningslinjer utgitt av Norsk barnelegeforening (므). Vi vil presisere at denne gjennomgangen ikke omfatter ikke-medikamentell behandling av manifestasjoner ved alvorlig malaria.

Da falciparummalaria er en potensielt dødelig infeksjon som krever rask diagnose og behandling, og stundom omfattende behandlingstiltak, utgjør behandling av denne plasmodiumarten største del av artikkelen.

Artikkelen bygger på en gjennomgang av litteratur funnet ved søk i PubMed og Cochrane library, epidemiologiske data fra Folkehelseinstituttet og forfatternes egne kliniske erfaringer. Den refererer også til Verdens helseorganisasjons behandlingsanbefaling fra 2010 (7.), men er tilpasset norske forhold.

\section{Plasmodium falciparum}

\section{ALVORLIG FALCIPARUMMALARIA}

En pasient med P falciparum som er allment påvirket i den forstand at vedkommende ikke er i stand til å svelge tabletter, har tegn til dysfunksjon fra vitale organer eller høy parasittemi (> $4 \%$ ), har alvorlig malaria.

Spesifikt defineres gjerne alvorlig falciparummalaria som funn av P falciparum i tykk og tynn dråpe eller ved positiv antigentest og ett eller flere av følgende kriterier: bevissthetsforstyrrelse, multiple kramper, lungeødem eller akutt lungesviktsyndrom (ARDS), sjokk, unormal blødning, nyresvikt, alvorlig anemi, icterus, hyperlaktatemi, metabolsk acidose, hypoglykemi, hemoglobinuri eller parasittemi $>4 \%(\underline{2}, \underline{8})$.

Pasienter med alvorlig malaria må overvåkes nøye og bør behandles i intensivavdeling. Figur 1 viser et blodutstryk fra en pasient med alvorlig falciparummalaria.

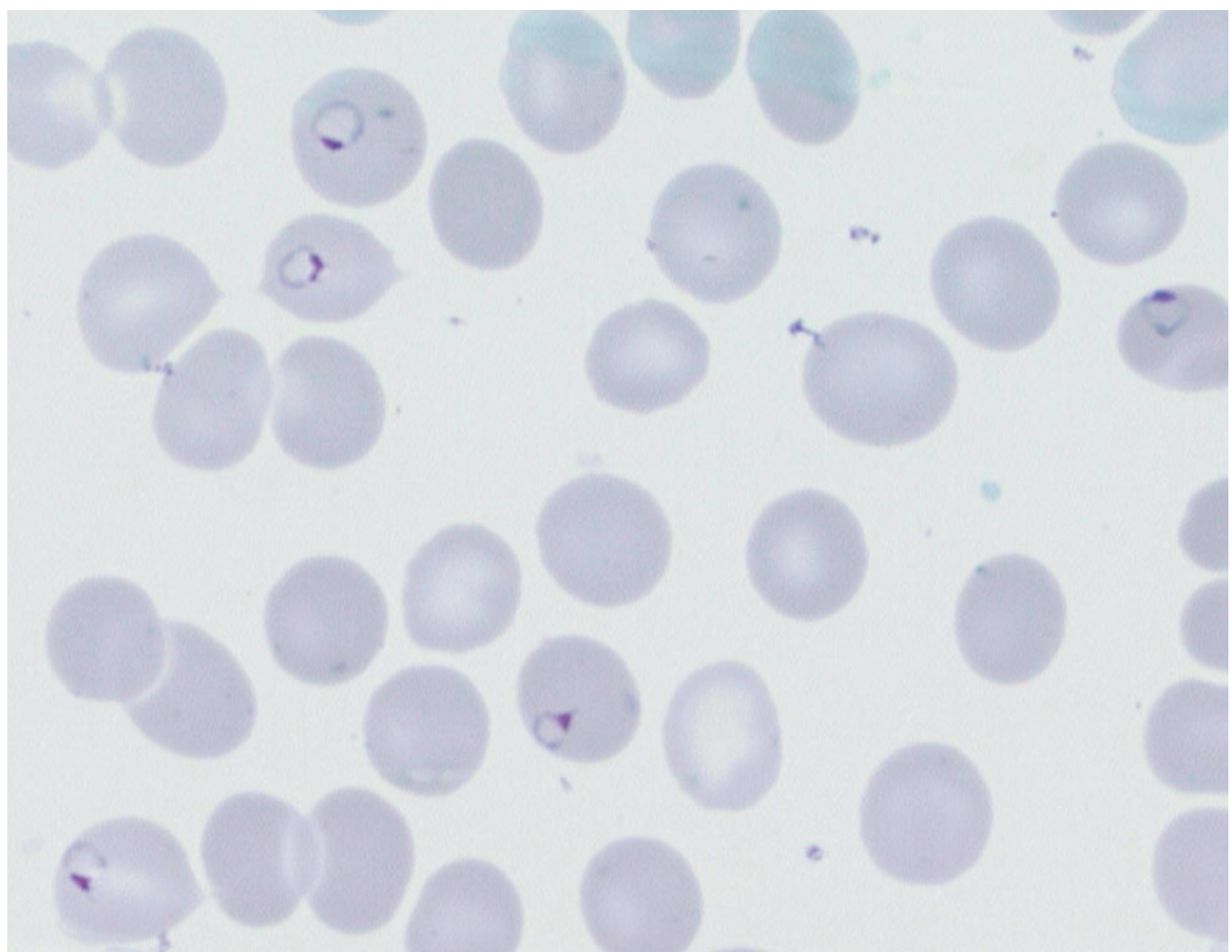

Figur 1 Plasmodium falciparum-ringformer i perifert blodutstryk hos gravid kvinne med alvorlig malaria og $14 \%$ parasittemi. Foto Kristine Mørch

Artesunat intravenøst bør være første medikamentvalg i behandling av alvorlig falciparummalaria (7..9.). Artesunat har lite bivirkninger, og pasienter behandlet med dette midlet hadde bedre overlevelse enn kininbehandlede i randomiserte studier i Asia og Afrika (므, $\underline{11})$. Medikamentet gir raskere parasittdrap enn kinin fordi det både er virksomt mot tidlige ringformer og mot de modne stadier av parasitten

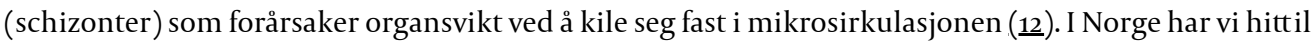
hatt god erfaring med artesunatbehandling ved alvorlig malaria (13).

Kinin intravenøst var det soleklare valg inntil for få år siden, og skal fortsatt brukes hvis man ikke har artesunat tilgjengelig, men man skal være oppmerksom på at kinin hos noen pasienter gir plagsom øresus og svimmelhet (cinchonisme), og at medikamentet må infunderes langsomt pga. risiko for arytmi (7.). Det skal samtidig gis glukoseinfusjon fordi kininbehandling gir risiko for alvorlig hypoglykemi. 
Så lenge pasienten får intravenøs behandling, kan både artesunat og kinin gis som monoterapi. Etter 1-3 døgns intravenøs behandling, når pasienten er i klinisk bedring og har parasittemi < 1 \%, går man over til behandling med et av de perorale antimalariamidlene som også brukes ved ukomplisert falciparummalaria, med varighet tilsvarende en full peroral kur ( $\operatorname{tab} 1 \operatorname{og} 2)(\underline{12}, 14$ ). Man skal være oppmerksom på mulige bivirkninger av artesunat, spesielt hvis intravenøs behandling i sjeldne tilfeller gis i mer enn tre dager. Dette er fordi man hos enkelte pasienter har observert alvorlig hemolyse i opptil fire uker etter behandling der kumulativ artesunatdose var en risikofaktor (15).

\section{Tabell 1}

Medikamentanbefalinger ved de ulike malariaspesies, og ved alvorlig og ukomplisert malaria

\begin{tabular}{|c|c|c|c|c|c|c|c|}
\hline $\begin{array}{l}\text { Spesies } \\
\text { (Plasmodium) }\end{array}$ & $\begin{array}{l}\text { Artesunat } \\
\text { intravenøst }\end{array}$ & $\begin{array}{l}\text { Kinin } \\
\text { intravenøst }\end{array}$ & $\mathrm{ACT}^{1}$ & Proguanilatovakvon & Meflokin & Hydroksyklorokiı & Primakin \\
\hline \multicolumn{8}{|l|}{ P falciparum } \\
\hline Alvorlig & 1. valg & 2. valg & - & - & - & Skal ikke brukes & Nei \\
\hline Ukomplisert & - & - & $\begin{array}{l}1 . \\
\text { valg }\end{array}$ & 2. valg & 2. valg & Skal ikke brukes & Nei \\
\hline \multicolumn{8}{|l|}{$P$ vivax } \\
\hline Alvorlig & 1. valg & 2. valg & - & - & - & - & $\mathrm{Ja}$ \\
\hline Ukomplisert & - & - & - & - & - & 1. valg & $\mathrm{Ja}$ \\
\hline P ovale & & & & & & 1. valg & Ja \\
\hline P malariae & & & & & & 1. valg & Nei \\
\hline \multicolumn{8}{|l|}{ P knowlesi } \\
\hline Alvorlig & 1. valg & 2. valg & - & - & - & - & Nei \\
\hline Ukomplisert & - & - & $\begin{array}{l}1 . \\
\text { valg }\end{array}$ & 2. valg & 2. valg & 2. valg & Nei \\
\hline $\begin{array}{l}\text { Dobbeltinfeksjon } \\
\text { eller uavklart } \\
\text { spesies }\end{array}$ & & & & & & & $\begin{array}{l}\text { Ved } \\
\text { mistenkt } \\
\mathrm{P} \text { vivax } \\
\text { eller } \mathrm{P} \\
\text { ovale }\end{array}$ \\
\hline Alvorlig & 1. valg & 2. valg & - & - & - & Skal ikke brukes & \\
\hline Ukomplisert & - & - & $\begin{array}{l}1 . \\
\text { valg }\end{array}$ & 2. valg & 2. valg & Skal ikke brukes & \\
\hline [i] & & & & & & & \\
\hline
\end{tabular}

[i] ${ }^{1}$ Artemeter-lumefantrin eller dihydroartemisinin-piperakin

\section{Tabell 2}

Dosering hos voksne pasienter av anbefalte medikamenter ved malaria $(\operatorname{tab} 1)(5,7)$

\begin{tabular}{|ll|}
\hline Medikament & Dosering \\
\hline Artesunat & $\begin{array}{l}2,4 \mathrm{mg} / \mathrm{kg} \text { intravenøst straks og etter } 12 \text { og } 24 \text { timer, deretter } \\
\text { en gang daglig, i vanligvis inntil } 3 \text { dager }\end{array}$ \\
\hline \multirow{3}{*}{ Kinin } & $\begin{array}{l}\text { Overgang til peroralt medikament som ved ukomplisert } \\
\text { falciparummalaria når pasienten kan svelge tabletter og } \\
\text { parasittemi }<1 \%\end{array}$ \\
& $1200 \mathrm{mg}(20 \mathrm{mg} / \mathrm{kg})$ infundert over $2-4$ timer som \\
& metningsdose, deretter $600 \mathrm{mg}(10 \mathrm{mg} / \mathrm{kg})$ med 8 timers \\
& intervall, total dose per døgn bør ikke overstige $1800 \mathrm{mg}$ \\
\hline
\end{tabular}




\begin{tabular}{|c|c|}
\hline Medikament & Dosering \\
\hline & $\begin{array}{l}\text { Overgang til peroralt medikament som ved ukomplisert } \\
\text { falciparummalaria når pasienten kan svelge tabletter og } \\
\text { parasittemi }<1 \%\end{array}$ \\
\hline \multirow{2}{*}{$\begin{array}{l}\text { Artemeter-lumefantrin (artemeter } 25 \mathrm{mg}, \\
\text { lumefantrin } 120 \mathrm{mg} \text { ) }\end{array}$} & 4 tabletter ved $0,8,24,36,48$ og 60 timer \\
\hline & Tas sammen med fettrik mat \\
\hline \multirow{2}{*}{$\begin{array}{l}\text { Dihydroartemisinin-piperakin } \\
\text { (dihydroartemisinin } 40 \mathrm{mg} \text {, } \\
\text { piperakintetrafosfat } 320 \mathrm{mg} \text { ) (14) }\end{array}$} & $36-75 \mathrm{~kg}: 3$ tabletter en gang daglig i tre dager \\
\hline & $75-100 \mathrm{~kg}: 4$ tabletter en gang daglig i tre dager \\
\hline & Tas utenom måltid \\
\hline \multirow[t]{2}{*}{ Meflokin } & $\begin{array}{l}\text { Initialt } 750 \mathrm{mg}(3 \mathrm{tbl}), \text { etter } 6-8 \text { timer } 500 \mathrm{mg}(2 \mathrm{tbl}) \text { og for } \\
\text { pasienter }>60 \mathrm{~kg} \text { etter ytterligere } 6-8 \text { timer } 250 \mathrm{mg}(1 \mathrm{tbl})\end{array}$ \\
\hline & Tas sammen med mat \\
\hline \multirow{2}{*}{$\begin{array}{l}\text { Proguanil-atovakvon (proguanil } 100 \mathrm{mg} \text {, } \\
\text { atovakvon } 250 \mathrm{mg} \text { ) }\end{array}$} & 4 tabletter en gang daglig i 3 dager \\
\hline & Tas sammen med fettrik mat \\
\hline \multirow[t]{2}{*}{ Hydroksyklorokin } & $\begin{array}{l}\text { Initialt } 600 \mathrm{mg} \mathrm{(}(4 \mathrm{tbl}) \text {, etter } 6 \text { timer } 300 \mathrm{mg} \text { ( } 2 \text { tbl). Deretter } \\
300 \mathrm{mg} \text { daglig i } 2 \text { dager }\end{array}$ \\
\hline & Tas sammen med mat \\
\hline \multirow[t]{3}{*}{ Primakin } & 15 mg per døgn i 14 dager \\
\hline & $\begin{array}{l}\text { Hvis ervervet i områder med primakinresistens (se tekst) eller i } \\
\text { områder hvor det er registrert tilbakefall etter vanlig dosering; } \\
22,5 \mathrm{mg} \text { eller } 30 \mathrm{mg} \text { eller 0,5 mg/kg per døgn i } 14 \text { dager }\end{array}$ \\
\hline & $\begin{array}{l}\text { Primakin er kontraindisert under graviditet og ved G6PD- } \\
\text { mangel }^{1}\end{array}$ \\
\hline
\end{tabular}

$[i]^{1}$ Glukose-6-fosfat-dehydrogenase-mangel

Både artesunat og kinin må skaffes på registreringsfritak, og alle akuttsykehus i Norge skal ha tilgjengelig ett av disse medikamentene, fortrinnsvis artesunat.

Blodutskifting eller erytrocyttaferese kan være indisert ved alvorlig malaria, selv om effekten ikke er dokumentert i randomiserte studier (16). Prosedyren utgjør en viss risiko, og vi støtter britiske retningslinjer som anbefaler å vurdere denne behandlingen hvis pasienten har > 30 \% parasittemi, eller $>10 \%$ parasittemi i tillegg til organdysfunksjon (17, 10 ), spesielt hvis pasienten behandles med kinin. På grunn av raskt innsettende parasittdrap vil det ved artesunatbehandling være mindre aktuelt med blodutskifting selv ved høy parasittemi.

UKOMPLISERT FALCIPARUMMALARIA

Pasienter med P falciparum parasittemi < 2 \% uten organpåvirkning kan behandles med perorale medikamenter $(\operatorname{tab} 1 \operatorname{og} 2)$ så lenge pasienten ikke kaster opp, men må overvåkes nøye med tanke på forverring (3).

Et artemisinin kombinasjonspreparat (ACT) er nå et utbredt førstevalg i behandling av ukomplisert falciparummalaria globalt, på grunn av rask og potent effekt, lite resistens og lite bivirkninger (7, 18 )-

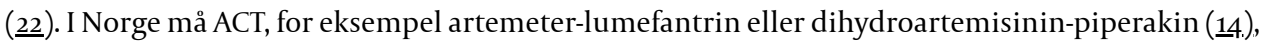
skaffes på registreringsfritak. Men har man det tilgjengelig, vil medikamentet for mange også her i Norge være et naturlig førstevalg ved peroral behandling av ukomplisert falciparummalaria fordi det gir raskest parasittdrap.

Proguanil-atovakvon og meflokin er imidlertid effektive alternativer $(\underline{18}, \underline{2} 3)$, men begge medikamenter virker langsommere enn ACT. Må man velge, vil man nok foretrekke proguanil-atovakvon, da meflokin hos enkelte pasienter kan gi plagsomme nevrotoksiske bivirkninger $(\underline{18}, \underline{24})$. Ved infeksjonsavdelingen ved Oslo universitetssykehus, Ullevål, som behandler om lag halvparten av malarariapasientene i Norge, har annenforfatter imidlertid ikke erfart vesentlige bivirkningsproblemer.

Det forekommer en sjelden gang at pasienten har brukt medikamentell profylakse og likevel fått malaria, og man bør da velge et annet medikament til behandling enn det som er gitt som profylakse. 
Proguanil-atovakvon bør velges hvis pasienten er smittet i Thailands grenseområder mot Myanmar og Kambodsja der det er rapportert utbredt resistens mot meflokin (25), og likeledes i Vest-Kambodsja der det er enkelte rapporter om artemisininresistens ( $\underline{\mathbf{2}} \mathbf{)})$.

Klorokin skal aldri brukes i behandling av falciparummalaria, uansett smittested, pga. utbredt klorokinresistens.

FALCIPARUMMALARIA OG GRAVIDE

Gravide er spesielt utsatt for alvorlig forløp ved falciparummalaria, spesielt lungeødem, hypoglykemi og hjernemalaria. Fordi det er uavklart om medikamenter som brukes ved malaria kan skade fosteret, må risikoen for dødelig forløp hos mor veies opp mot risikoen for medikamentell fosterskade. Av aktuelle falciparummedikamenter er det kun kinin og klindamycin som i følge WHO helt trygt kan brukes i hele svangerskapet (7.). Fosterskadelig effekt ved bruk av artemisininderivater og ACT har ikke vært påvist (27.)-(29.), men WHO etterlyser flere studier med medikamentene tidlig i graviditeten (7.).

Alvorlig malaria må også hos gravide, som hos ikke-gravide, selvsagt behandles umiddelbart med parenterale medikamenter, artesunat eller kinin (7.). Også hos gravide bør artesunat være førstevalget, selv om det foreløpig er en viss usikkerhet knyttet til sikkerheten i første trimester $(7, \underline{28}, 29$.$) . Som terapi$ etter intravenøs behandling med artesunat (eller kinin) vil vi gi artemeter-lumefantrin som er det ACT man har mest erfaring med i behandling av gravide (27.), eller i 2. og 3. trimester eventuelt meflokin.

Ved ukomplisert falciparummalaria anbefaler WHO i første trimester peroral behandling med kinin i kombinasjon med klindamycin i sju dager, men angir artemeter-lumefantrin som et aktuelt alternativ (7.). I andre og tredje trimester anbefales artemeter-lumefantrin, bedømt ut fra både effekt og sikkerhet $(7,27$.$) . Da kinin kan gi plagsomme bivirkninger i form av cinchonisme, og peroral kinin sjelden er$ tilgjengelig ved norske sykehus, vil vi ved ukomplisert falciparummalaria gi artemeter-lumefantrin under hele graviditeten, alternativt meflokin i 2. og 3. trimester.

\section{Andre plasmodier}

De siste årene er det bare meldt 5-10 tilfeller årlig av infeksjon med andre plasmodier enn P falciparum til MSIS (1) . De fleste skyldes P vivax som er den vanligste malariaparasitten utenfor Afrika. Infeksjoner med P ovale og P malariae forekommer svært sjelden i Norge, og vi har ennå ikke hatt et eneste importtilfelle av P knowlesi.

Behandling av infeksjoner med andre plasmodier enn P falciparum er som regel nokså uproblematisk. Pasientene frembyr vanligvis ikke alvorlige sykdomsbilder, unntatt ved P knowlesi-infeksjon og i meget sjeldne tilfeller ved P vivax-malaria.

Pasientene kan ofte behandles ambulant med perorale medikamenter. Klorokin er fortsatt hovedmidlet i behandlingen, og resistens mot klorokin er foreløpig et begrenset problem.

PLASMODIUM VIVAX

De fleste vivaxpasienter vi ser i Norge, har ervervet sin infeksjon i Asia. Klorokin er standardbehandlingen. Etter at klorokinfosfattabletter ble avregistrert i 2009, er hydroksyklorokin eneste registrerte klorokinmiddel ( $\operatorname{tab} 1$ ).

I Oceania, Indonesia og Peru er klorokinresistente P vivax utbredt, og vivaxpasienter derfra bør behandles med meflokin, proguanil-atovakvon eller med et ACT-preparat f.eks. artemeter-lumefantrin (30).

Behandlingen av vivaxmalaria innebærer også behandling av parasitter i leveren (hypnozoitter), som klorokin ikke påvirker. Utrydding av hypnozoittene med primakin er nødvendig for å hindre tilbakefall. Standardbehandlingen av vivaxmalaria er derfor hydroksyklorokin pluss primakin.

Standarddoseringen av primakin er $15 \mathrm{mg}$ daglig i 14 dager. Det har imidlertid vist seg at pasienter fra enkelte områder i Oceania og Sørøst-Asia kan få tilbakefall etter gjennomført 14 dagers primakinbehandling. Pasienter fra disse områdene bør derfor få en høyere dose (tab 1) (7.).

Primakin kan gi hemolytisk anemi hos personer som har glukose-6-fosfat-dehydrogenase (G6PD)mangel. Prevalensen av defekten varierer sterkt rundt omkring i verden, med høyest forekomst i Afrika, Midtøsten og Sørøst-Asia. I Norge er forekomsten meget lav, men som en følge av emigrasjon fra høyendemiske områder, vil G6PD-mangel finnes i enkelte befolkningsgrupper. Vi anbefaler at personer som har genetisk bakgrunn fra områder med høy forekomst av G6PD-mangel, testes før man gir primakin. Primakin skal ikke gis til gravide.

P vivax, som vanligvis gir moderat sykdom, kan av ukjente årsaker en sjelden gang gi meget alvorlige sykdomsmanifestasjoner med cerebral affeksjon, anemi, icterus, alvorlig trombocytopeni m.m. (30 $)$-(32). Står man overfor en pasient med alvorlig vivaxmalaria, er behandlingen som ved alvorlig og komplisert falciparuminfeksjon (7.). I tillegg gir man primakin. 
P ovale er, uavhengig av hvor infeksjonen er ervervet, følsom for klorokin (7.,33). Behandlingen er derfor med hydroksyklorokin, og da $\mathrm{P}$ ovale, som $\mathrm{P}$ vivax, danner hypnozoitter, må pasientene også få primakin i 14 dager (7.). Det er ikke rapportert at P ovale kan ha nedsatt følsomhet, verken overfor klorokin eller primakin (7.).

\section{PLASMODIUM MALARIAE}

P malariae-malaria behandles med hydroksyklorokin (tab 1), da det hittil kun har vært en enkeltstående rapport om tilfeller av klorokinresistent P malariae i Sumatra, Indonesia (7.34). P malariae danner ikke hypnozoitter, og pasienten skal derfor ikke ha primakinbehandling.

\section{PLASMODIUM KNOWLESI}

Det finnes foreløpig ikke internasjonale retningslinjer for behandling av knowlesimalaria. En nylig rapport fra Malaysia viste at klorokin og kinin peroralt var effektivt i ukompliserte tilfeller, men at pasientene ble raskerere parasittfri med ACT, og ved alvorlig knowlesimalaria ga artesunat raskere parasittdrap enn kinin (35).

Raskt parasittdrap er viktig fordi parasittene har kort livssyklus (24 timer), og pasientene kan i løpet av få dager utvikle svær parasittemi og kliniske og laboratoriemessige tegn til alvorlig sykdom. Står man overfor en slik pasient, må sykdommen behandles som en alvorlig P falciparum-infeksjon og det må straks gis parenteral behandling med artesunat eller kinin (35)-(37).

\section{Behandling når spesiesdiagnosen er uavklart}

Som regel kan man ved hjelp av mikroskopi og/eller hurtigtest, samt anamnese og klinisk observasjon nokså sikkert fastslå hvilken plasmodiumspesies pasienten er infisert med. Men med lav parasittemi kan det av og til være vanskelig. Hvilken behandling gir man da?

Som regel kan man ikke helt sikkert utelukke infeksjon med P falciparum, særlig vil det gjelde pasienter fra Afrika, og man må velge behandling som er effektiv mot P falciparum (tab 1).

Hvorvidt pasienten skal få primakinbehandling, må avgjøres i hvert enkelt tilfelle.

\section{Behandling av dobbeltinfeksjoner}

Det hevdes at dobbeltinfeksjoner, dvs. samtidig infeksjon med to ulike plasmodier, er vanlig i endemiske områder (7.). Mistenker man dobbeltinfeksjon, er det selvsagt at pasienten i slike tilfeller får effektiv behandling for en eventuell P falciparum-infeksjon. Falciparummedikamenter vil være virksomme mot alle spesies, men vil ikke utrydde hypnozoitter. Konkluderer man med at pasienten var infisert med P vivax eller P ovale må man derfor supplere med primakin.

\section{Tabell}

\begin{tabular}{l}
\hline Hovedbudskap \\
\hline - Malaria i Norge skyldes hyppigst P falciparum som raskt kan bli livstruende \\
- Alvorlig malaria behandles med artesunat, alternativt kinin, intravenøst \\
- Perorale artemisinin kombinasjonspreparater eller alternativt proguanil-atovakvon eller meflokin, \\
anbefales ved ukomplisert falciparummalaria \\
- Klorokin er fortsatt hovedmidlet ved malaria som skyldes andre spesies enn P falciparum eller P knowlesi
\end{tabular}

\section{LITTERATUR}

1. Smittevernboka. Oslo: Folkehelseinstituttet, 2010.

2. Bruneel F, Tubach F, Corne P et al. Severe imported falciparum malaria: a cohort study in 400 critically ill adults. PLoS ONE 2010; 5: e13236. [PubMed] [CrossRef] 
3. Moore DA, Jennings RM, Doherty TF et al. Assessing the severity of malaria. BMJ 2003; 326: 8o8-9. [PubMed] [CrossRef]

4. Jensenius M, Rønning EJ, Blystad $\mathrm{H}$ et al. Low frequency of complications in imported falciparum malaria: a review of 222 cases in south-eastern Norway. Scand J Infect Dis 1999; 31: 73-8. [PubMed] [CrossRef]

5. Forening for utgivelse av Norsk legemiddelhåndbok. Norsk legemiddelhåndbok for helsepersonell 2010. Oslo: Fagbokforlaget, 2010: 88-91.

6. Klingenberg K, Mørch K. Malaria (2009). Revidert veileder. Norsk barnelegeforening, 2009. www.legeforeningen.no/id/110284.o (16.1.2012).

7. Guidelines for the treatment of malaria, second edition. 2010. www.who.int/malaria/publications/atoz/9789241547925/en/index.html (16.1. 2012).

8. Severe falciparum malaria. Trans R Soc Trop Med Hyg 2000; 94 (suppl 1): 1-9o. [PubMed] [CrossRef]

9. Sinclair D, Donegan S, Lalloo DG. Artesunate versus quinine for treating severe malaria. Cochrane Database Syst Rev 2011; nr. 3: CDoo5967. [PubMed]

10. Dondorp AM, Fanello CI, Hendriksen IC et al. Artesunate versus quinine in the treatment of severe falciparum malaria in African children (AQUAMAT): an open-label, randomised trial. Lancet 2010; 376:1647-57. [PubMed] [CrossRef]

11. Dondorp A, Nosten F, Stepniewska K et al. Artesunate versus quinine for treatment of severe falciparum malaria: a randomised trial. Lancet 2005; 366: 717-25. [PubMed] [CrossRef]

12. Hess KM, Goad JA, Arguin PM. Intravenous artesunate for the treatment of severe malaria. Ann Pharmacother 2010; 44: 1250-8. [PubMed] [CrossRef]

13. Mørch K, Strand $\emptyset$, Dunlop O et al. Severe malaria and artesunate treatment, Norway. Emerg Infect Dis 20o8; 14: 1816-8. [PubMed] [CrossRef]

14. Eurartesim. www.ema.europa.eu/ema/index.jsp?

curl=pages/medicines/human/medicines/oo1199/human_med_oo1450.jsp\&mid=WCobo1aco580o1d124(26.1. 2012).

15. Zoller T, Junghanss T, Kapaun A et al. Intravenous artesunate for severe malaria in travelers, Europe. Emerg Infect Dis 2011; 17: 771-7. [PubMed]

16. van Genderen PJ, Hesselink DA, Bezemer JM et al. Efficacy and safety of exchange transfusion as an adjunct therapy for severe Plasmodium falciparum malaria in nonimmune travelers: a 10-year single-center experience with a standardized treatment protocol. Transfusion 2010; 50: 787-94. [PubMed] [CrossRef]

17. Mørch K, Feruglio SL, Ormaasen V et al. Alvorlig falciparummalaria behandlet med utskiftingstransfusjon. Tidsskr Nor Lægeforen 2002; 122: 999-1001. [PubMed]

18. Lalloo DG, Shingadia D, Pasvol G et al. UK malaria treatment guidelines. J Infect 2007; 54: 111-21. [PubMed] [CrossRef]

19. Ding XC, Beck HP, Raso G. Plasmodium sensitivity to artemisinins: magic bullets hit elusive targets. Trends Parasitol 2011; 27: 73-81. [PubMed] [CrossRef]

20. White NJ, van Vugt M, Ezzet F. Clinical pharmacokinetics and pharmacodynamics of artemether-lumefantrine. Clin Pharmacokinet 1999; 37: 105-25. [PubMed] [CrossRef]

21. Sinclair D, Zani B, Donegan S et al. Artemisinin-based combination therapy for treating uncomplicated malaria. Cochrane Database Syst Rev 2009; nr. 3: CDoo7483. [PubMed]

22. McCarthy JS, Sekuloski S, Griffin PM et al. A pilot randomised trial of induced blood-stage Plasmodium falciparum infections in healthy volunteers for testing efficacy of new antimalarial drugs. PLoS ONE 2011; 6: e21914. [PubMed] [CrossRef]

23. Osei-Akoto A, Orton L, Owusu-Ofori SP. Atovaquone-proguanil for treating uncomplicated malaria. Cochrane Database Syst Rev 2005; nr. 4: CDoo4529. [PubMed]

24. Toovey S. Mefloquine neurotoxicity: a literature review. Travel Med Infect Dis 2009; 7: 2-6. [PubMed] [CrossRef]

25. Price RN, Uhlemann AC, Brockman A et al. Mefloquine resistance in Plasmodium falciparum and increased pfmdr1 gene copy number. Lancet 2004;364: 438-47. [PubMed] [CrossRef]

26. Dondorp AM, Nosten F, Yi P et al. Artemisinin resistance in Plasmodium falciparum malaria. N Engl J Med 20o9; 361: 455-67. [PubMed] [CrossRef]

27. Piola P, Nabasumba C, Turyakira E et al. Efficacy and safety of artemether-lumefantrine compared with quinine in pregnant women with uncomplicated Plasmodium falciparum malaria: an open-label, randomised, non-inferiority trial. Lancet Infect Dis 2010; 10: 762-9. [PubMed] [CrossRef]

28. Orton LC, Omari AA. Drugs for treating uncomplicated malaria in pregnant women. Cochrane Database Syst Rev 2008; nr. 4: CDoo4912. [PubMed]

29. Clark RL. Embryotoxicity of the artemisinin antimalarials and potential consequences for use in women in the first trimester. Reprod Toxicol 2009; 28: 285-96. [PubMed] [CrossRef]

30. Price RN, Douglas NM, Anstey NM. New developments in Plasmodium vivax malaria: severe disease and the rise of chloroquine resistance. Curr Opin Infect Dis 2009; 22: 430-5. [PubMed] [CrossRef]

31. Poespoprodjo JR, Fobia W, Kenangalem E et al. Vivax malaria: a major cause of morbidity in early infancy. Clin Infect Dis 2009; 48:1704-12. [PubMed] [CrossRef]

32. Anstey NM, Russell B, Yeo TW et al. The pathophysiology of vivax malaria. Trends Parasitol 2009; 25: 220-7.

[PubMed] [CrossRef]

33. Siswantoro $\mathrm{H}$, Russell B, Ratcliff A et al. In vivo and in vitro efficacy of chloroquine against Plasmodium malariae and P. ovale in Papua, Indonesia. Antimicrob Agents Chemother 2011; 55: 197-202. [PubMed] [CrossRef] 
34. Maguire JD, Sumawinata IW, Masbar S et al. Chloroquine-resistant Plasmodium malariae in south Sumatra, Indonesia. Lancet 2002;360: 58-6o. [PubMed] [CrossRef]

35. William T, Menon J, Rajahram G et al. Severe Plasmodium knowlesi malaria in a tertiary care hospital, Sabah, Malaysia. Emerg Infect Dis 2011; 17: 1248-55. [PubMed] [CrossRef]

36. Cox-Singh J, Davis TM, Lee KS et al. Plasmodium knowlesi malaria in humans is widely distributed and potentially life threatening. Clin Infect Dis 2008; 46: 165-71. [PubMed] [CrossRef]

37. Myrvang B. En femte plasmodiumart som kan gi malaria. Tidsskr Nor Legeforen 2010; 130: 282-3. [PubMed]

Publisert: 27. mars 2012. Tidsskr Nor Legeforen. DOI: 10.4045/tidsskr.11.0589

Mottatt 13.5. 2011, første revisjon innsendt 31.10. 2011, godkjent 19.1. 2012. Medisinsk redaktør Siri Lunde.

(C) Tidsskrift for Den norske legeforening 2023. Lastet ned fra tidsskriftet.no 26. april 2023. 